\title{
La Olla Deleitosa: un caso de mutación textual en el ensayo identitario chileno*
}

\author{
Federico Pastene Labrín**
}

\begin{abstract}
Resumen
Este artículo analiza cómo la obra La Olla Deleitosa. Cocinas mestizas de Chile de Sonia Montecino se destaca por ser un caso de ensayo identitario chileno que evidencia significativos cambios a nivel formal y temático, por cuanto se desarrolla un proceso de mutación textual que innova y transgrede la configuración del ensayo identitario mediante el empleo de estrategias discursivas como la simbolización disciplinaria, multigenericidad y multimodalidad, revitalizando el ensayo de la identidad chilena en el actual contexto del Bicentenario nacional.
\end{abstract}

Palabras clave: mutación textual, ensayo, identidad chilena.

\section{La Olla Deleitosa: one case of textual mutation in the chilean identity essay}

\begin{abstract}
This article examines how the work La Olla Deleitosa: Cocinas mestizas de Chile, Sonia Montecino illuminates changes in the process of identity construction in the Chilean essay. Significant changes at the formal and thematic levels are actualized through the development of a textual mutation process. This innovative process reconceptualizes the identity essay through the use of discursive strategies like multi-dimensional, multimodal, and disciplinary symbolization and serves to revitalize the Chilean identity essay in the current context of the national bicentennial.
\end{abstract}

Key words: textual mutation, essay, chilean identity.

Recibido: 11-10-2013 Aceptado: 22-10-2013

* Este artículo forma parte de una sección de la tesis doctoral del autor Mutación textual en el discurso ensayístico de la identidad chilena, realizada en el Programa de Doctorado en Ciencias Humanas Mención Discurso y Cultura de la Universidad Austral de Chile, y patrocinada por el Dr. Iván Carrasco Muñoz. Asimismo, forma parte del Proyecto de Investigación DIUBB No 104125 1/1, de la Universidad del Bío-Bío, que me permitió realizar una actualización e indagación más profunda del tema en cuestión.

Una versión de este trabajo fue leída en el Sexto Encuentro Nacional de Estudios del Discurso, organizado por el Capítulo Chileno de la Asociación Latinoamericana de Estudios del Discurso (ALED) y la Universidad de Chile, Santiago, octubre 2010.

** Chileno, Doctor Ciencias Humanas Mención Discurso y Cultura, Académico del Departamento de Artes y Letras, Universidad del Bio-Bio, Chillán, Chile, fpastene@ubiobio.cl 


\section{Introducción}

En este artículo analizamos cómo la obra La Olla Deleitosa. Cocinas mestizas de Chile, de la antropóloga y escritora chilena Sonia Montecino, evidencia importantes cambios en su conformación estructural y temática, ya que presenta una mutación textual que innova y transgrede la configuración del ensayo identitario mediante el empleo de estrategias escriturales como la simbolización disciplinaria, multigenericidad y multimodalidad, revitalizando el ensayo de la identidad chilena en el actual contexto del Bicentenario nacional.

El abordaje del estudio sobre el ensayo de identidad chilena considera, al menos, dos supuestos fundamentales. Primero, un supuesto textual: el discurso involucra un dinamismo denotado en cambios que se producen en su conformación esquemático-semántica mediante determinados procedimientos; y, segundo, un supuesto pragmático, donde estos cambios obedecen a objetivos e intenciones variadas surgidos en determinados momentos y que tensionan el sistema imperante. Es decir, la naturaleza dinámica de los discursos y las relaciones entre forma y función lingüística. El género concebido como un fenómeno dinámico, sujeto a cambio y adaptación por los participantes (Wang, 2009). Se considera la forma y función ensayo en tanto construcción textual que, al tiempo que interpreta un pensamiento y lo traduce, considera y analiza acontecimientos, sucesos e ideas.

Al respecto, no podemos obviar que el discurso se configura sobre la base de una doble dimensión que se interrelaciona y que le da sentido mutuo como es la estructura esquemática y semántica (Van Dijk, 1990), en nuestro caso, ensayo e identidad, respectivamente. El ensayo es un tipo de texto que no tiene una superestructura fija, dado que es el particular modo de organizar su macroestructura la que va a determinar formas variadas de organización ensayística (Vila y Pilia, 2008).

Estos dos términos (ensayo e identidad) están interrelacionados desde $\mathrm{su}$ intensificación en los procesos emancipatorios americanos y en la construcción de un discurso muy fructífero que unificó y al mismo tiempo distinguió las nacionalidades que fueron surgiendo en América Latina. Dos conceptos que hoy deben escrutarse en un período postransitorio latinoamericano desde el 'ensayismo de tierra firme' al 'ensayismo de las orillas' (Weinberg, 2004). Es decir, el ensayo de la identidad chilena 
en un período de profundos cambios e inestabilidades, de mutación, de hibridación y de honda reflexión en los bicentenarios americanos.

\section{Antecedentes. El ensayo identitario}

El ensayo representa un discurso singular y polémico para la teoría y la crítica, puesto que en más de una oportunidad hace evidentes y problematiza varias cuestiones que otros géneros permiten considerar transparentes, o cuando menos posibles de postergar a la hora del análisis. Tal es, entonces, la reflexión que compartimos con Weinberg (2006) en el sentido de volver sobre estos 'casos especiales' o 'atípicos' de la literatura -diríamos del discurso y de la cultura en general- que presentan dificultades, por ejemplo, a la hora de clasificarlos, por lo tanto, es necesario aproximarnos al sistema, estudiar nuevas posibilidades y plantear propuestas capaces de clarificar este tipo de texto tan huidizo. Han existido posturas que han tratado de reducir al ensayo a un espacio neutral y descontextualizado, o de reducirlo a lecturas que atiendan de manera excluyente ya sea a la forma o al contenido, sin lograr tender los necesarios puentes entre ellos, o también con otra dimensión clave como el contexto sociocultural.

Desde un punto de vista canónico, el ensayo ha sido definido mediante un concepto que posibilita abarcar tanto al ensayo literario como al ensayo escolar, al ensayo de Montaigne como al ensayo del siglo XX: "texto en prosa que manifiesta un punto de vista bien fundamentado, bien escrito y responsable del autor respecto de algún asunto del mundo" (Weinberg, 2006: 20). De partida, esta es una definición breve y muy general, que en el fondo no da cuenta de las múltiples problemáticas que tanto el ensayo literario como el no literario, al que hemos llamado multidisciplinario, presentan en el día de hoy. Su delimitación conceptual comienza a tener dificultades cuando tratamos de enriquecer esta caracterización con otras propiedades como las demandas de la forma artística, el trabajo con el lenguaje y la voluntad de estilo que muchas veces tienden a desaparecer cuando pedimos redactar un ensayo con un propósito más instrumental, como el ensayo argumentativo a nuestros estudiantes en un examen. Otro tanto sucede con aquellos rasgos que una época o, antes bien, una comunidad hermenéutica específica considera decisivos, otorgándole, por ejemplo, en el ensayo de aproximación más disciplinario el sello de su campo. 
Por nuestro lado, en Chile, en este último tiempo -sobre todo desde el inicio de este siglo- ha habido un interés creciente por el tema de la identidad chilena, tópico en verdad recurrente en nuestra tradición cultural e intelectual, pero que desde nuestro parecer se intensificó por la proximidad del Bicentenario de la República, ocasión, pues, propicia para ir analizando, reflexionando, discutiendo, en el fondo, construyendo y reconstruyendo nuestra concepción de identidad nacional.

Sin embargo, los estudios actuales sobre el ensayo identitario chileno son escasos. Cabe destacar a tres críticos: Roberto Hozven, Mario Lillo y Javier Pinedo (1988, 2000a, 2000b, 2002, 2006). Este último en varios artículos analiza las principales obras de los últimos cincuenta años en el contexto de construir una 'historia de las ideas de Chile', realizando una clara periodización del mismo. Por otra parte, Hozven (2001) y Lillo (2003) se han aventurado por un análisis más literario-retórico al estudiar cómo en el ensayo chileno se construye la idiosincrasia a través de alegorías identitarias.

Pero este soporte que sustenta la identidad chilena, que es el ensayo, ha tenido dificultades para abordar tan discutido contenido. El problema surge cuando el lector actual es capaz de identificar o discriminar el tema principal de una obra, pero entra en conflicto cuando, por ejemplo, no es capaz de distinguir el género discursivo que respalda el tema identitario: fenómeno al que hemos llamado incertidumbre genérica; o cuando comparamos un ensayo tradicional identitario con uno de reciente publicación y vemos que las estrategias escriturales innovan o transgreden regularidades que hasta ese momento habían sido empleadas sin distorsión. Los cambios, las transformaciones, las nuevas experimentaciones y confusiones no solo llegan al lector más o menos informado, sino también impregnan al mismo escritor, quien mediante el empleo de determinados procedimientos escriturales confronta su concepción de identidad con la herencia, con la tradición, con el canon.

Una mirada tipológica del arte literario contemporáneo hace notar que los géneros convencionales han dejado de ser fijos y se han mezclado con otros de estructura similar o distinta, surgiendo otros géneros y textos intermedios, confusos, ambiguos, híbridos, y que estas transformaciones se originan en contacto con discursos convencionalmente visualizados como no-literarios. Un acontecer semejante se registra en ámbitos científicos vinculados con la literatura, donde estos hechos presentan 
indicios de mayor intensidad y complejidad. La crisis y ruptura de los modelos canónicos de la literatura y del discurso mediante los mecanismos de la parodia, la distorsión, la reproducción en serie, la mezcla, fusión o hibridismo de los textos y géneros dominantes y estables de la tradición, los diferentes modos de la transtextualidad, entre otros, han dividido o debilitado la estructura y los tipos de los textos conocidos, han difuminado los lindes y abierto las fronteras entre ellos, al mismo tiempo que han cuestionado la influencia, el sentido y la validez de términos como verosimilitud, realismo, ficción, referente, veracidad, y su vinculación necesaria con tipos de oralidad y de escritura (Carrasco, 2002).

Los cambios que vive el discurso literario producido en América Latina resultan transgresores, rupturistas, abriéndose un abanico de nuevas posibilidades estéticas en una profunda tensión entre tradición y modernidad. Para Volpi la ficción en nuestro continente vive un momento inédito:

Por primera vez no se es víctima de un deber ser novelístico. Se desvanecieron las normas, los cánones, las prohibiciones -escribe así o te fusilamos, no escribas asá o te ignoramosy, salvo un puñado de críticos ponzoñosos y resentidos -es decir, un puñado de críticos-, nadie pretende fijar un baremo para medir a los escritores del continente. Por primera vez, insisto, uno puede elegir cualquier deriva y ser recibido con la misma legitimidad (o la misma indiferencia): los sutiles decoradores de miniaturas; los búfalos de la intriga policíaca; los que narran con pericia lo que sea; los vanguardistas de última hora; los etéreos de la metaficción; los mutantes de la novela y el ensayo ${ }^{1} ;(.$.$) fuera de dos o tres apocalípticos que$ se rasgan las vestiduras, claman ante la decadencia, acusan al mercado de todos nuestros males -antes eran el comunismo y el imperialismo- y onanistas rabiosos, escriben reseñas con el único fin de triturar a sus vecinos, nadie lamenta el cambio. $(2009,77)$

En el presente siglo, la construcción del discurso identitario chileno -nos referimos al conjunto de escritores que mediante el discurso

1 La cursiva es nuestra. 
han propuesto o recogido una concepción de identidad nacional- ha proseguido su camino con bastante asiduidad motivado, entre otros, por el polo de atracción que ha significado el Bicentenario de la República². Sin embargo, el ensayo identitario chileno actual evidencia significativas transformaciones mediante rasgos singulares que denotan una evolución de este tipo de discurso en su dimensión textual, cognitiva y sociocultural. Los ensayistas actuales, entre ellos, Sonia Montecino, mantienen una preocupación por plasmar las características de un 'ser nacional' o de una 'nacionalidad', pero, al mismo tiempo, tienden, pues, a enfatizar y modificar cómo construir esta identidad nacional mediante el discurso, destacando los mecanismos o estrategias de elaboración textual y la participación de una mayor cobertura de esferas socioculturales por dejar huellas -desde su área- sobre esta temática.

\section{Estrategias discursivas de mutación textual}

3.1. Concepto de mutación textual'. De partida, concebimos 'mutación textual' como un proceso que consiste en la producción de cambios a nivel de la organización esquemática que opera en la estructura de las obras del conjunto textual ensayístico actual que aborda la identidad chilena, produciéndose una modificación de su superestructura mediante el empleo de mecanismos discursivos o estrategias escriturales diversas (simbolización disciplinaria, multigenericidad y multimodalidad, en el caso de Sonia Montecino) que hacen que estos procedimientos, en ocasiones, destaquen por sobre la organización semántica de los discursos.

En otras palabras, este proceso involucra el análisis del funcionamiento textual de un género inestable como es el ensayo, específicamente, en un conjunto textual o tipo de ensayo como el identitario chileno actual. Asimismo, es necesario revisar qué elementos configuran la invariante genérica que nos permite decir que son ensayos, pero, sobre todo, nuestro foco de interés radica en cuáles son las variantes

2 Nos referimos, por ejemplo, a El Cuerpo de Chile de Marco Antonio De la Parra (2002), Chile, ¿de qué estamos hablando? Retrato de una transformación asombrosa de Patricia Politzer (2006), Comunidad, familia y nación en el Bicentenario. El sueño chileno de Eugenio Tironi (2005), Los nuevos chilenos y la batalla por sus preferencias de Pablo Halpern (2002), entre otros.

3 El concepto de mutación textual lo hemos generado a partir de aportaciones similares que se han estado haciendo en otros ámbitos. Cabe destacar a Carrasco (2003) con su concepción de mutación disciplinaria, Alvarado (2002) con mutación discursiva y Barreto (2007) con mutación semiótica. 
textuales del tipo de ensayo en cuestión; a esto último atribuimos los procedimientos anteriores.

3.2. La obra en estudio. La primera vez que conocimos el libro La olla deleitosa. Cocinas mestizas de Chile (2005), debemos declarar que fue una sorpresa por el variopinto textual que contiene. La primera lectura se centró en las recetas que la obra presenta ilustradas con llamativas imágenes en papel cuché. Por supuesto que este inicial acercamiento fue cándido y desprovisto de un aparataje teórico. Pero, ¿cuál fue la sorpresa?: que el libro era más que un simple recetario de cocina que a veces acostumbramos conocer, ubicado precisamente en las estanterías de las librerías en la sección de gastronomía.

La obra, a través de 206 páginas, despliega una serie de recursos textuales que no pueden dejarnos indiferentes al abordar un género como el ensayo y, sobre todo, si el tema es la identidad. Esta última preocupación ya la ha tratado en sus escritos Sonia Montecino, donde sobresale Madres y huachos. Alegorías del mestizaje chileno (1996) y también el haber sido compiladora de Revisitando Chile. Identidades, mitos e historias de Cuadernos Bicentenario (2003). Es decir, la preocupación idiosincrásica ha estado de modo permanente en esta escritora, pero ahora se presenta en un nuevo discurso. $\mathrm{O}$, mejor dicho, ¿qué es lo nuevo del discurso identitario de Montecino?

3.3. Estrategia 1: Simbolización disciplinaria. La obra estudiada forma parte de la colección "La cultura en la cocina" de Editorial Catalonia (Chile), la que presenta un planteamiento desde donde se sitúa, por tanto, La olla deleitosa: "La cocina no es sólo un procedimiento técnico que permite que los productos alimenticios se transformen en platos y recetas; es, por sobre todo, un lenguaje en el que se expresa la cultura humana. Los gustos, la estética, las combinaciones de sabores, los condimentos preferidos, las maneras de mesa, son gestos sociales que se relacionan con la historia y con la transmisión de los signos que distinguen a una comunidad de otra" (Montecino 2005, 3). Es decir, la cocina involucra un conjunto de signos que identifican a una comunidad cultural, que posee identidad. Sin embargo, el simbolismo que encierra, aquellas significaciones implícitas, debe ser escrutado mediante el otorgamiento de un sentido que proviene del contacto, la experiencia, y de la interacción social y cultural. 
La olla deleitosa forma parte de los postulados de una colección dedicada a la cocina, pero que presenta e indaga más allá de un mero recetario o manual. La autora, en el cuerpo de su obra, plantea ya reveladores indicios de su proyecto escritural donde cocina $\mathrm{y}$ simbolismo se engranan para construir un discurso identitario: "Las piedras y el símbolo de la olla son dos grandes dominios en que se asientan las significaciones históricas y sociales del discurso alimenticio chileno. Con sentidos propios de cada realidad local, se conjuntan y disyuntan para especificar gestos humanos que hablan de las identidades y de la producción inagotable de lo cultural, expresada en la cocina" (9).

Postulábamos al inicio que en La olla deleitosa se registra de modo dominante un procedimiento discursivo de simbolización disciplinaria, en concreto, una simbolización culinaria, al expresar la autora que tras lo que consumimos entraña una manera de ser y de distinguirnos. Asistimos, pues, a una semiótica de lo culinario, donde tras cada forma, aroma y color subyace un discurso identitario chileno revelador. Los símbolos constituyen, por cierto, signos cuya presencia evoca otra realidad sugerida o representada por ellos. Y esta es efectivamente, lo que nos identifica.

En consecuencia, debemos revelar a continuación estos signos culinarios, qué es lo que cada uno de ellos representa, qué nos dice de nosotros, cómo nos define identitariamente. Un juego que va desde lo oculto a lo visible. Y de qué manera se va vislumbrando una concepción identitaria nacional. A continuación, unos casos:

La calapurca, v. gr., posee el siguiente significado: "Como hemos dicho, la relevancia cultural de este plato es su permanencia en el tiempo y la identidad local del mismo, un plato indígena, un plato del norte; también su importancia reside en ser una mezcla que pone en relación diversos productos marcados simbólicamente. Así, la calapurca representa una suerte de síntesis entre pasado y presente, una juntura de lo andino, lo hispano y lo "chileno'" (53). Es un plato elaborado a partir de piedras calientes donde se mezcla con alimentos para su cocción. Denota principalmente la influencia indígena en nuestra conformación identitaria que ha traspasado el tiempo manteniéndose como un fiel testigo de esta implicancia cultural. Al mismo tiempo, es un plato que simboliza el sincretismo cultural, ya que de un origen precolombino no 
tuvo problemas para ser asimilado por los españoles y así integrarse definitivamente a nuestro acervo culinario.

Otra clave identitaria es la que encierra el cebiche, plato conocido en el norte chileno, y que también su preparación sugiere un código de discriminaciones culinarias nacionales que distinguirán lo que es 'chileno' y lo que es 'peruano', haciéndose de partida imposible determinar los 'orígenes' del plato, sino más bien la autora se centra en los simbolismos del mismo. De esta manera, se despliega un abanico de significaciones claramente identificables: "Así, el código de los colores coloca lo 'chileno' al lado de lo blanco; el de las formas, junto a lo pequeño; el de las texturas, a lo suave; el de los ingredientes, a la mezcla -la cebolla blanca confundida con la carne blanca-; y el de los sabores, a lo salado" (75). Entonces, se desarrolla una antinomia sígnica culinaria, una contraparte que definiría ambas nacionalidades: "Por su parte, y en oposición, lo 'peruano' se caracteriza por lo oscuro (el pescado negro y la cebolla morada), lo grande, lo duro, lo áspero y lo agridulce. Así en el lenguaje de las 'pequeñas' diferencias, lo chileno resulta de una suerte de 'blanqueamiento' de una operación en donde el cebiche se 'civiliza' (doble cocción de limón) y la propiedades crudas pasan a una derivación líquida, a una 'copa' que evoca de ese modo a una bebida con propiedades más 'medicinales' que alimenticias"' (75).

La calapurca y el cebiche son dos comidas del norte de nuestro país con denotadas significaciones culinarias que no concluye allí, sino siguiendo el recorrido territorial que emplea la autora, nos acercamos a la zona central. Esta es considerada como una construcción histórica y cultural que "exporta" al norte y al sur del país un conjunto de símbolos con los que se identifica lo "chileno", explicando con ello que la 'esencia' identitaria chilena estaría específicamente entre la zona comprendida desde el Aconcagua hasta el río Bío-Bío, ríos entre los cuales se conformó el núcleo idiosincrásico nacional.

En este sentido, el plato prototípico por antonomasia sería la cazuela: "que representa en sí mismo una unidad, una identidad, pero especifica también diferencias locales, regionales y personales. Porque se prepara de distintas formas. (...) Hay antecedentes que nos permiten plantear que la cazuela constituye el paradigma del mestizaje mapuche-español, el "abrazo" caliente de las tradiciones locales y las europeas (97). La cazuela, herencia hispánica que se traspasó a la cocina mapuche, se 
'criollizó' convirtiéndose por así decirlo en el plato más común en todos los sectores sociales, por cierto los populares. El chileno es en el fondo un ser mestizo surgido de la unión mapuche y española. La cazuela nos recuerda este antecedente que nos define como pueblo. Aquí la autora se acerca a la concepción indígena y mestiza de nuestra identidad nacional.

En suma, la naturaleza, preparación y consumo de estos alimentos entraña un signo de identidad, revelando ciertas particularidades que se proyectan y que emanan de su singular conformación, destacando, sobre todo, la herencia mestiza y cómo se han ido adaptando, asimilando a nuestra cultura.

3.4. Estrategia 2: Multigenericidad. Este rasgo forma parte de esta posibilidad de introducir en el discurso literario, en este caso, ensayístico, elementos variables, es decir, convertir a La olla deleitosa es un texto multigenérico, primando, por lo tanto, un espacio dialógico complejo (Fréris, 2009). La obra se organiza mediante la presencia de variados géneros discursivos que, de forma articulada, sirven para ilustrar o apoyar las aseveraciones o interpretaciones que realiza la autora. Es decir, esta multigenericidad tiene un propósito bien definido: constituyen "fuentes de interpretación" en la construcción del discurso culinario identitario chileno. Encontramos junto con el discurso ensayístico central y dominante, poemas, testimonios, recetas, mitos, leyendas, digresiones, exordios y notas que se presentan de modo organizado en los tres grandes capítulos de la obra que han sido denominados: 1. "Andanzas nortinas", 2. "Caminata por la zona central" y 3. "Caminando por el sur".

En sus primeras páginas se deja entrever que el género dominante -o macrogénero- es el ensayo, con un indicio inicial: la plena conciencia de que frente al objetivo principal de su trabajo no puede pretender agotar el tema, desafío que dejará ranuras para futuras indagaciones. Es una aproximación al objeto de estudio, del cual no hay suficientes soportes empíricos, ¿y por qué tendrían que haberlos si su intención no es un tratado de culinaria sino una aproximación mediante la reflexión e interpretación?: "Es imposible abarcar el amplio universo de la antropología de la alimentación, sobre todo, considerando la precariedad de conocimientos que nos asiste 4 . Por ello, hemos realizado un 'recorte'

4 La cursiva es nuestra. 
y no nos hemos dedicado a reconstruir los menús locales, regionales o nacionales, sino más bien a reconstruir ciertos platos" (10).

Además, el complejo proceso hermenéutico emprendido en la obra tiene fases bien delimitadas que se articulan bajo un horizonte común que es la traducción identitaria nacional a través de la cocina, recurriendo a diversas fuentes de las cuales metodológicamente podrá visualizar aquellos rasgos ocultos de nuestra idiosincrasia, pero siempre con la convicción de que será una aproximación, solo 'conjeturas', no certezas científicas:

Desde esa mirada fragmentaria en el espacio y en el tiempo es que hacemos el recorrido, esperando abrir algunas brechas y conjeturas que interroguen a la gramática con que se construye el lenguaje de lo culinario en Chile. Anhelamos con este texto entreabrir el abigarrado mundo que incorporamos cotidianamente en nuestro cuerpo y en nuestra psiquis, trayendo a la lectura memorias arqueológicas, escritas y orales, que nos ayudan al develamiento de por qué comemos lo que comemos y cómo eso nos constituye en quienes somos. (10)

La cocina proporciona así un territorio privilegiado para analizar "la densidad cultural" de un grupo humano, por cuanto se inscribe dentro del plano donde los símbolos se reproducen, se transforman o mezclan. El significado de determinadas comidas las constituye precisamente en emblemáticas para sus consumidores, para quienes tienen un sentido: no son simples signos de una comunidad, sino que son experiencias de un lenguaje compartido. Eso es lo que deseamos comunicar en este ensayo, revisitando platos considerados como propios por los habitantes de una región; porque entendemos que las identidades (locales, familiares, nacionales, etc.) se materializan en aquellos alimentos que se aprecian y en las ideologías que sustentan su incorporación mediante el consumo. (16)

Por lo tanto, la escritura, y también la lectura de esta obra, es una travesía semiótica notable, si consideramos el presente texto como signo: formas, colores, aromas rememorados, situaciones pasadas y presentes, 
evocaciones, texturas, voces y escrituras que se conjugan para dar cuerpo a este recorrido donde arte y ciencia tienden a articularse, confundiendo los límites genéricos: ¿es un ensayo o una obra de divulgación científica? ¿Cómo se produce el traslado de un género a otro? ¿Por qué al lector le provoca incertidumbre la delimitación o definición autorial?: "Por último, sin el proyecto Fondecyt $\mathrm{N}^{\mathrm{o}}$ 1030567, que comparto con María Elena Acuña, no habría sido posible trazar el camino de reflexión $n^{5}$ sobre antropología culinaria en Chile del cual este libro es tributario" (14). Sin más, para la autora es un ensayo -cuyo acto de habla predominante es la reflexión, tal como lo enfatiza- que se desprende de un estudio científico anterior, que no puede ser publicado a modo de estudio crítico, sino que debe ser adecuado a la audiencia que se dirige:

Esta versión popular del ensayo La olla deleitosa. Cocinas mestizas de Chile, emerge como necesidad de ampliar su circulación y de abrir su acceso a un público más grande, pero también al anhelo de difundir una mirada antropológica sobre las cocinas nuestras. Se trata de una reflexión ${ }^{6}$ situada en un momento en que la mundialización de los mercados y el quiebre de muchas fronteras culturales marca la existencia de nuestras sociedades. Es un tiempo propicio para pensar en las identidades ${ }^{7}$, precisamente porque ellas suponen cambios constantes y construcción de horizontes, donde lo propio y lo 'ajeno' se entreveran en procesos que ponen en cuestión o proponen límites a lo que es "nuestro" y a lo que es de los "otros". (15)

Por lo tanto, la alimentación es un lenguaje cargado de significaciones y vastos sentidos que la escritora desea revelar mediante estrategias discursivas diversas y que compromete una forma de "pensarnos" a nosotros mismos. Es decir, identidad y alimentación se unen mediante el discurso que interpreta sus potencialidades.

En cuanto a la presencia de poemas, estos pertenecen a dos grandes poetas chilenos, Gabriela Mistral y Pablo de Rokha, que tienen la función de constituir epígrafes que introducen al tema tratado. Por ejemplo, 
de Mistral "En tierras blancas de sed" o "Elogio de las piedras": "Las piedras amodorronadas, ricas de sueños/como la pimienta de esencia, graves de sueños/como la piña de fragancia" (43). "Prosiguen "Elogio del agua", "Luz de Chile", "Canción del maizal", "El mar". De Pablo de Rokha, fragmentos de su monumental "Epopeya de las comidas y bebidas de Chile": "Porque en Antilhue fructifica una longaniza tan exquisita como en Chillán, la longaniza que se comía en los solares de la gran ciudad funeral y fue como el toro de Miura: lo único definitivo, por lo cual yo prefiero adobado el lomo aliñado en Lautaro o Galvarino o Temuco, obteniéndolo con cerdo sureño, oceánico". Ambos poetas cultivan la imaginación poética cósmica: Mistral, la imaginación terrestre. Todo lo asociado a la tierra habla en su poesía cargada de rudeza y sacrificio, como las piedras, por ejemplo. En cambio, De Rokha cultiva la imaginación ígnea: todo la poesía está impregnada por el quemante fuego por el cual los alimentos transitan, cambian y están listos para el deleite comensal. Los poemas son parte de la memoria culinaria, son testimonios de la palabra vivida por el poeta que Montecino utiliza como complemento en su obra.

Por su parte, los testimonios constituyen la materia prima de recorrido culinario. Son fuentes primarias que la escritora aprovecha justo para precisar o destacar un rasgo culinario. Las distintas voces manifiestan un relato desde la propia experiencia como hacedores de lo culinario, productores y también consumidores. Detrás de ellos, conviven del mismo modo, tradiciones diversas que emanan de sus experiencias. Es un discurso auténtico y revelador: "El cebiche que nosotros hacemos acá es diferente al del sur; acá en el norte el cebiche es característico, todos los domingos se come cebiche -y en todas las clases sociales-, "pejerrey al dedo" y un "plato de picante" (Relato que proviene de Humberto Morales, antiguo cocinero de barcos pesqueros y vendedor de mariscos y pescados" (76).

Las recetas constituyen otro recurso discursivo que se despliega en el texto y que son extraídas a partir del testimonio de los propios informantes como de colecciones ya editadas (recetarios de cocina). Este es un texto híbrido conformado por una serie de elementos (ingredientes) que son los descriptores, seguido de una secuencia temporal que son las instrucciones. Hay recetas sobre el cebiche, la calapurca, la cazuela de ave (escrita también en mapudungún), cazuela de vaca, cazuela de cordero, charquicán, estofado de San Juan, entre otras. Este tipo de texto 
viene a ser un eje central de la obra, pero no se nutre solamente de estas recetas como pareciera, ya que se complementa con otros discursos más las ilustraciones gráficas y otras a todo color.

El texto incluye también relatos de ficción proveniente de las culturas culinarias andinas y del resto del territorio nacional. Se deja testimonio de cómo la comida está asociada íntimamente al imaginario mítico y legendario de las comunidades. Historias que construyen identidad y sentido de pertenencia a sus habitantes, tales como el mito sobre la Llama celestial, "La olla deleitosa", "La ciudad deleitosa" y "El torito de Caliboro". Estos textos fundamentalmente provienen de la tradición oral que Montecino ha sabido también rescatar, preservar y difundir.

Por último, las notas denotan el origen o el pre-texto de carácter científico que dio origen a este ensayo. Son fuentes que sustentan determinadas afirmaciones y referencias a otros autores fundamentalmente del ámbito antropológico. Se enriquece este género con comentarios de la propia autora, remitiéndose a sus propias obras, fuentes de testimonios orales a través de entrevistas efectuadas por la propia investigadora, y el sustento histórico que ha dejado huella de una cultura culinaria chilena.

En suma, este variopinto textual tiene una función clara y específica de constituir un conjunto de argumentos que orientan el carácter holístico de la interpretación culinaria. O mejor dicho, la multisensorialidad de la cocina, impregnada en la historia, en las vivencias, en el imaginario mítico, en arte, en el grupo, en la familia, en la nación.

3.5. Estrategia 3: Multimodalidad. Del mismo modo, para facilitar esta participación del lector, La olla deleitosa se convierte en un texto multimodal que combina recursos verbales escritos con recursos electrónicos como el email. La autora aprovecha sin tapujos los recursos de las nuevas tecnologías de la información y la comunicación y las integra a su proyecto escritural, innovando absolutamente una tradición cultural. Aquí nos encontramos con un síntoma más de mutación textual que posee interesantes implicancias teóricas. Aunque Kress y Van Leeuwen (1998) postulen que "todos los textos son multimodales", en este caso, se trata de entender la multimodalidad como el punto de partida de una reflexión teórica y clasificación a partir de una nueva semiótica que pone en tela de juicio la primacía de la expresión verbal. El cambio teórico es desde una teoría que solo dio cuenta del lenguaje hacia una teoría que pueda dar cuenta de la gestualidad, el habla, las imágenes, 
la escritura y sus diversos modos de expresión y comunicación como la escritura digital, entre otros (Williamson, 2005) ${ }^{8}$. La autora guardará en su reservorio datos de sus lectores tal vez para una tercera edición más completa del libro.

Desde el punto de vista de la producción lingüística escrita, esta estrategia escritural se conecta de modo inmediato con dos enfoques muy precisos que orientan la construcción textual: una que señala que la escritura es un producto donde lo que interesa es llegar al texto terminado y definitivo; en cambio, el otro enfoque precisa que para llegar a un producto, que será inacabado, por cierto, se requiere de unas etapas en el proceso de escritura. En nuestro caso, desde el punto de vista del proyecto escritural de Montecino, se trata de integrar comentarios al desarrollo del texto. La escritura ensayística como proceso y producto al mismo tiempo (cf. Parodi, 2003). El lector se convierte en escritor y también partícipe de la construcción discursiva de la identidad a partir de sus conocimientos y experiencias sobre lo culinario.

Es un recurso discursivo que efectivamente innova la ensayística, evento inédito que demanda detenernos, y es el de considerar de partida a La olla deleitosa como un texto abierto en el sentido literal de la palabra, que no está definitivamente terminado, sino que necesariamente requiere de una participación activa y efectiva por parte del lector, cumpliendo un rol vedado: productor empírico de textos en el circuito de la comunicación artística ensayística. Este aspecto se denota cuando la autora, utilizando el discurso del testimonio deja en blanco el resto de la página con líneas y al final aparece indicada una dirección electrónica. He aquí el ejemplo:

* Héctor González me llevó al puesto de don Humberto en las pescaderías frente al puerto de Arica; ambos sostuvieron una discusión sobre cuál pescado era mejor para el cebiche; según don Humberto, los de

8 En el ámbito anglosajón se está trabajando con una corriente analítica de estudio desprendida del análisis del discurso, que es el 'análisis del discurso multimodal' que ha comenzado a preocuparse de estos fenómenos, de la integración del lenguaje verbal y otros con el soporte digital, informático, mediático e hipertextual. Aquí algunos aprontes sobre esta nueva orientación: "Multimodal discourse analisis is a fairly new and rapidly developing perspective on discourse whuch hola taht meanings are created in texts and interactions in a complex interplay of semiosis across multiple modes which incluye but are not limited to griten and spoken language. In seeking to understand this interplay it has integrated insights from a number of more established approaches to discourse as well as other social sciences".(...) "Despite its relatively short history, multimodal discourse analysis has also had an important influence on other approaches and fileds, most notably in the area of literacy and the growing interest in digital literacies" (Jewitt and Kress 2003:233). 
carne blanca, pero él prefiere lenguado. Héctor dice que la corvina. Pero los nombres del sargo, el allanque, la palometa, el peje sapo, el hacha se deslizan en sus opiniones también. En el pejerrey al dedo coinciden y recuerdan una infancia en la que la feracidad del mar era casi un mito que hacía la felicidad ariqueña e iquiqueña.

\section{Comentarios a: olladeleitosa@gmail.com (66).}

Implícitamente, el testimonio posee una fuerza perlocutiva, es decir, es una apelación al lector para que entre en la discusión, para que él sea también un protagonista en la construcción o reconfiguración identitaria, desde su propia visión influida por su posición cultural y geográfica, expresado, en fin, a partir de su invaluable caudal cognitivo culinario. Al responder estas líneas está participando del tejido que reconstruye discursivamente la identidad. Con su ejercicio deja de ser un lector ideal, invisible, sino que se identifica con nombre, con casilla electrónica.

Aquí la transgresión es novedosa y se confronta con el ensayo tradicional. La autora implícitamente invita al lector a realizar un discurso del comentario para recabar más opiniones e informaciones sobre la cultura culinaria nacional, lo invita a proseguir la discusión entablada en el testimonio?.

9 Sin lugar a dudas, la obra, con el empleo de este recurso ha generado una desestabilización de lo que tradicionalmente se ha concebido como la lectura. Es algo más allá de la recepción. ¿No habrá entonces otras alternativas? ¿No es hora de que el lector ingrese a la página, ingrese a la obra, sea un sujeto más participativo de las experiencias estéticas?

La Estética de la Recepción postula que el texto solo es obra por la actualización o concreción que lleva a cabo el lector. El texto es, pues, una premisa básica o condición necesaria insoslayable para constituir la obra... Pero a su vez sin la transformación del texto por el receptor, no hay obra. Es así como Sánchez (2005) discute esta teoría que, evidentemente, entregó aportes significativos a la comprensión del fenómeno literario, pero también tiene sus limitaciones. Entre estas últimas se encuentra el hecho de que la Estética de la Recepción sólo fija su atención en el aspecto significativo, semántico de la obra de arte, pero no en su dimensión formal y material. Otra limitancia es que esta teoría no presta atención a las condiciones sociales donde ocurre la práctica artística: "no ve, por tanto, que nuestra sociedad enajenada, mercantilista, es hostil a la creatividad tanto en la producción como el consumo, o en términos estéticos, tanto en la creación como en la recepción" (Sánchez, 2005:11).

En este sentido, para Sánchez (2005) la solución a estos problemas pasa por un cambio de perspectiva y plantea sustituir la "Estética de la Recepción" por una "Estética de la Participación", en la que el receptor no sólo transforme la obra por vía de la interpretación de su significado, sino también a la obra misma: "como objeto sensible, material, dotado de cierta forma" y contribuye a transformar a través del proceso mismo de la praxis estética. En consecuencia, Montecino, en La olla deleitosa, está generando las condiciones para que el lector sea más que un receptor, sea un participante mediante el empleo del uso que se le pueden sacar a las nuevas tecnologías. 
En suma, la dominante identitaria culinaria presentada en estos platos que nos refiere el texto es la preeminencia en nuestra conformación histórico-cultural que es el mestizaje, a su vez matizado por algunas influencias de otras culturas, principalmente europeas. De norte a sur en nuestro territorio se teje un entramado de comidas unidas a costumbres, relatos, mitos y leyendas, testimonios, recetas, y lo que también puede aportar el lector ayuda finalmente a construir un texto único y diverso al mismo tiempo. Un texto que se acerca al ensayo por su objetivo de reflexionar simbólicamente la identidad chilena a través de los platos más típicos, pero también está llevando a cabo un proceso de innovación textual genérica que implica una mutación textual de la serie ensayística identitaria chilena, tal como lo hemos planteado.

\section{Conclusiones}

En síntesis, en la obra La Olla deleitosa. Cocinas mestizas de Chile se ha desarrollado un proceso de mutación textual ensayística que pretende innovar el conjunto textual tradicional que trata la identidad chilena al considerar determinados procedimientos discursivos como la simbolización disciplinaria, donde la cocina se transforma en una gran metáfora que debe escrutarse extrayendo los signos que crean la identidad, unida a la multigenericidad y multimodalidad, cuyo engranaje de textos, producción textual y recurso electrónico harán que el lector se sume con su propio discurso a la reconfiguración identitaria, convirtiéndose en elementos variantes de esta serie ensayística. En este sentido, uno de los rasgos invariantes que dan unidad a la obra y pertenencia al género son la reflexión e interpretación que principalmente efectúa la autora en torno a las comidas chilenas como manifestaciones que crean identidad.

Por último, el texto estudiado es una manifestación concreta de cómo el escritor actual se abre a las reglas convencionales del género, en este caso, del ensayo, sobrepasándolas, creando nuevas formas expresivas o fusionando elementos tradicionales para dar origen a una nueva genética, la de subvertir el género en provecho del texto, generando una diversidad artística y estética, que supere la monotonía de la expresión única. 


\section{Bibliografía}

Alvarado, Miguel (2002). “Mutación discursiva en las Ciencias Sociales chilenas. Lecturas de un texto de Francisco Gallardo". Revista Signos: Estudios de Lingüística 51-52. 3-20.

Barreto, Juan (2007). "Mutación semiótica de un texto: Tensión entre el Popol Vuh y el Pop Wuj". Contribuciones desde Coatepec 12. 39-50.

Carrasco, Iván (2002). "Interdisciplinariedad, interculturalidad y canon en la poesía chilena e hispanoamericana actual", Estudios filológicos 37. 199-210.

. (2003b). "La antropología poética como mutación disciplinaria", Estudios Filólogicos 38. 7-17.

Fréris, Georges (2009). “Du genre conventional au texte multigénérique”. Caitele Echinox 16. 61-66.

Hozven, Roberto. (2001). “Alegorías identitarias en cuatro ensayos chilenos", Anales de literatura chilena 2. 207-219.

Jewitt, C. \& Kress, G. (2003). Multimodal literacy, New York: Peter Lang.

Kress, G. \& Van Leeuwen (1998). "Front pages: (The critical) analysis ofnewspaper layout". En Allan Bell \& Peter Garret (eds.), Approaches to media discourse, Oxford: Blackwell.

Lillo, Mario (2003). “Tropos y alegorías en el ensayo histórico chileno: La Fronda Aristocrática de Alberto Edwards". Taller de letras 32. 27-35.

Montecino, Sonia (1996). Madres y huachos. Alegorías del mestizaje chileno, Santiago: Sudamericana.

. (2003). Revisitando Chile. Identidades, mitos e historias. Santiago: Cuadernos Bicentenario.

. (2005). La olla deleitosa. (Cocinas mestizas de Chile). Santiago: Catalonia. 
Parodi, Giovanni (2003). Relaciones entre lectura y escritura. Una perspectiva cognitiva y discursiva. Valparaíso: Ediciones Universitarias de Valparaíso.

Pastene, Federico (2010). Mutación textual en el discurso ensayístico de la identidad chilena. Valdivia. Universidad Austral de Chile. Tesis Doctoral.

Pinedo, Javier (1988). “La ensayística y el problema de la identidad 19601988”, Gómez Martínez, José Luis y Pinedo, Javier. Chile: 1968-1988. University of Georgia, Series on Hispanic Thought 22-25. 231-264.

. (2000a). "Ensayo chileno y política". Cánovas, Rodrigo, Roberto Hozven (eds.). Crisis, apocalipsis y utopías. Fines de siglo literatura latinoamericana. Santiago, Pontificia Universidad Católica de Chile, 429-435.

. (2000b). "Pensar en (la) transición. Intelectuales chilenos durante el proceso de transición a la democracia. 1990-1999". UNIVERSUM 15. 189-232.

. (2002). "Cinco momentos claves en el ensayo literario chileno contemporáneo". Vilanova, Antonio (coord.). Actas del X Congreso de la Asociación Internacional de Hispanistas 4. 893-906.

. (2006). "Los intelectuales y la creación de la identidad Nacional". Revista UNIVERSUM 1 (21). 245-247.

Sánchez, Adolfo (2005). De la estética de la recepción a una estética de la Participación. México: UNAM-FFYL.

Vila, María y Pilia, Nelda (2008). Travesías del ensayo latinoamericano del siglo XX. Neuquén: Ediciones Universidad Nacional del Comahue.

Van Dijk, Teun (1990). Estructuras y funciones del discurso. Una introducción interdisciplinaria a la lingüística del texto y a los estudios del discurso. México: Siglo XXI.

Volpi, Jorge (2009). El insomnio de Bolívar. Cuatro consideraciones intempestivas sobre América Latina en el siglo XXI. Buenos Aires: Debate. 
Wang, Sungsonn (2009). "Text types and dynamism of genres" in Renkema, J. (ed.). Discourse of course. An overview of research in discourse studies, Philadelphia: John Benjamins Publishing Company.

Weinberg, Liliana (2004). “Ensayo e identidad. Dos términos en correlación". En Cabrera, Patricia (coord.). Pensamiento, cultura y literatura en América Latina. México: CIICH-UNAM y Plaza y Valdés. . (2006). Situación del ensayo. México: Centro Coordinador Difusor de Estudios Latinoamericanos. UNAM.

Williamson, Rodney (2005). “A qué llamamos discurso en una perspectiva multimodal? Los desafíos de una nueva semiótica". Actas Encuentro Internacional de la Asociación Latinoamericana de Estudios del Discurso (ALED). Santiago. $<$ www.aledar.com $>$. 